\title{
Classic publications and scientometrics in orthopaedics
}

\author{
Andreas F. Mavrogenis ${ }^{1} \cdot$ Andrew Quaile $^{2} \cdot$ Marius M. Scarlat $^{3}$
}

Published online: 13 November 2020

(C) SICOT aisbl 2020

Orthopédie (orthopaedics), a French term coined by seventeenth-century physician Nicholas Andry de BoisRegard derived from the Greek words ỏ $\rho \theta$ ó $\varsigma$ (orthos; correct or straight), and $\pi \alpha \iota \delta$ íov (paidion; child) has shown substantial advances over the past decades. Many subspecialties have appeared and evolved, with significant progress in clinics, as well as in basic science and research [1-6]. Consequently, high-volume orthopaedic surgeons have contributed to highvolume journals with a significant number of high-quality clinical and research papers [4, 7-9]. Since its foundation in 1977, International Orthopaedics, the official journal of Société Internationale de Chirurgie Orthopédique et de Traumatologie (SICOT) has a 43-year publication history of offering a significant contribution to this field of medicine through its numerous high-quality papers. Each year, the journal receives $>3000$ high-quality paper submissions for consideration; of than number, approximately 400 of the highestquality papers qualify for publication; the number of times a paper is cited is widely used to measure a journal's scientific impact, as well the impact of the paper and the publishing authorship [8, 10-12].

Bibliometric analyses map the literature around a specific field of research and provide variables with respect to the citations numbers, which are the citations count, subject matter and type, country and institution of origin, and authorship of the published papers $[13,14]$. Such analyses provide insights into which type of articles represent the highest academic impact. In these analyses, classic papers that is articles that have attained a classic status in the orthopaedic heritage have been identified.

Marius M. Scarlat

mscarlat@gmail.com

1 First Department of Orthopaedics, National and Kapodistrian University of Athens, School of Medicine, Athens, Greece

2 Spineworks, Hampshire Clinic, Basingstoke, Hampshire, UK

3 Clinique St. Michel, Groupe ELSAN, Toulon, France

\section{The classic papers}

By definition, a classic is an excellent model that was judged over a period of time to be of the highest quality and outstanding of its kind. In medical writing, a classic paper is a highly cited publication; it is a model paper that has stood the test of time to be of recognized and established value, having a great impact on the field, and influencing research, education, practice, and opinions $[15,16]$. In orthopaedics, a classic paper is highly cited paper and provides an exceptional insight into the history and development of practice. Classic papers have made long lasting and game changing contributions to clinical practice and research, having long term visibility after publication. They highlight the topics that have made the most impact on the clinical practice and provide a fascinating account of the qualities and of the authors achievements. They inspire surgeons to evaluate and eventually change their standard practice, to recognize key advances and significant developments in orthopaedics, to provide an important message, and/or to add a useful prospective on historical developments. Definitely, a classic paper is not about playing a numbers game or a citation quotient; in contrast, it embraces the most in orthopaedic specialty $[16,17]$.

The top-100 list of classic papers is dominated by protein biochemistry literature. The 1951 paper describing the Lowry method for quantifying protein remains practically unreachable at number 1 classic paper with more than 305000 citations [18]. In orthopaedics, prosthetic surgery of the hip has shown the greatest level of interest $[17,19]$, with highly cited papers such as the Brooker et al. paper for the ectopic ossification of the hip [20]. In musculoskeletal oncology, typical example of classic papers are the Enneking et al. papers for the surgical staging of musculoskeletal sarcomas and the functional classification of reconstructions after tumors resections [21, 22].

\section{The citations}

Citations (referencing), in which one paper refers to earlier works, are the standard means by which authors acknowledge 
the source of their methods, ideas and findings, and are often used as a rough measure of a paper's importance. After publishing his papers on evaluation of science by citation metrics [23] Eugene Garfield founded in 1956, the Institute for Scientific Information (ISI), located in Philadelphia, Pennsylvania. ISI formed a major part of the science division of Thomson Reuters. In 2016 Thomson Reuters sold its intellectual property and science division to Clarivate Analytics.

In the current way of measuring science citations are very important. A citation is an alphanumeric expression that acknowledges the relevance given by the author to the work of others on a topic of discussion in which the citation appears. The primary objective of a citation is to credit other authors with ideas and innovations about which they have previously published. It is an act of intellectual honesty at the opposite of plagiarism and citations fraud [17].

However, citations are often biased; $<20 \%$ of the cited papers are actually read by the authors; $3-60 \%$ (mean, $>20 \%$ ) of citations have errors; citations are often chosen for convenience rather than for appropriateness; easily available papers such as open access papers and papers written in English language are most often cited; and $>25 \%$ of citations are standard references such as classic papers. To avoid citations biases, citations should be chosen by the quality of the cited papers, and not by social factors, exchange authorship, or strategic considerations [24, 25].

It is unclear how a paper becomes a classic especially acknowledging the fact that citation counts are biased with confounding factors. In the current era, many rankings and alternative metrics are available including scholar and social metrics. These incorporate search engines that trace citations from a much greater (although poorly characterized) literature base, including books, websites, papers and meeting proceedings [26].

\section{Measuring a citations classic paper}

A classic paper is cited almost without thinking about it. Therefore, measuring the classic status of a paper by the number of times the paper is cited is one approach to meeting this definition [27, 28]. A citations classic paper is identified by the Science Citation Index (SCI) or its larger version, the Science Citation Index Expanded (SCIE), the Social Sciences Citation Index (SSCI), or the Arts \& Humanities Citation Index (A\&HCI). The journals indexed by the SCIE and SSCI citations indexes are described as the world's leading journals.

The larger version of the Science Citation Index (Science Citation Index Expanded) covers more than 8,500 notable and significant journals, across 150 disciplines, from 1900 to the present. The index is made available online through different platforms, such as the Web of Science and SciSearch. This database allows a researcher to identify which later articles have cited any particular earlier article, or have cited the articles of any particular author, or have been cited most frequently. Subsets of this database are also available, termed "Specialty Citation Indexes" such as the Neuroscience Citation Index and the Chemistry Citation Index. The Social Sciences Citation Index (SSCI) is a citation index originally developed by the Institute for Scientific Information from the Science Citation Index. It is currently a commercial citation index product of Clarivate Analytics. It is a multidisciplinary index that covers more than 3,000 social science journals across 57 disciplines in the social sciences from 1988 to present. The Arts \& Humanities Citation Index (A\&HCI), also known as Arts \& Humanities Search, is a citation index, with abstracting and indexing for more than 1800 arts and humanities journals across 28 arts and humanities disciplines. Part of this database is derived from Current Contents records. Subjects covered are the Arts, Humanities, Language (including Linguistics), Poetry, Music, Classical works, History, Oriental Studies, Philosophy, Archaeology, Architecture, Religion, Television, Theater, and Radio. Available citation (source) coverage includes articles, letters, editorials, meeting abstracts, errata, poems, short stories, plays, music scores, excerpts from books, chronologies, bibliographies and filmographies, as well as citations to reviews of books, films, music, and theatrical performances. This database can be accessed online through Web of Science. It provides access to current and retrospective bibliographic information and cited references. It also covers individually selected, relevant items from approximately 1,200 titles, mostly arts and humanities journals but with an unspecified number of titles from other disciplines.

There is an argument of whether citation analysis that is measuring the numbers (count and density) of citations should be considered as a significant influence on what constitutes a classic paper [16, 29, 30]. For scientific research, the impact factor of a journal has become a controversial area of debate with critics for a number of faults and manipulations. The citations count is an alternative to rank an article, authors and journals; the more cited an article, the greater the impact factor of the journal and the more renowned the authors they become. The citations density is determined by the number of citations over the number of years a work has been published. It allows for the relative impact of an article regardless of year of publication; however, although a recently published article may have a high citation density because of its newness it usually takes a few years to acquire classic status [16]. Additionally, citations numbers do not account for self-citations, citations in textbooks and lectures; there is a clear temporal effect in citation analysis with the most recent articles being at a disadvantage, there is an obvious bias in favor of English language journals and journals included in 
computerized databases, and older publications are no longer cited with the same frequency because their findings become incorporated into the body of current knowledge or they become so familiar that they do not need a citation (the "obliteration by incorporation" phenomenon) [13, 17, 31-35]. Last, the numbers of citations are influenced by confounding factors that preclude their use as a measure of quality of the research and its influence on current literature and clinical practice. These include the types of publications, the time of publication, the size and field of the study, the journal in which the article is published, and the novelty of a subspecialty. Publication of randomized trials, meta-analyses and basic science reports may lead to significantly more citations than other study types [36].

\section{Publishing a citations classic paper}

Citation rates differ for each discipline. The number of citations indicating a classic in an orthopaedic subspecialty might be lower than the number required to make it a classic in a larger field of orthopaedics specialty. In general, a publication cited more than 400 times should be considered a classic; but in some fields with fewer researchers, 100 citations might qualify a classic work. Obviously, review articles, introductory articles, editorials, guidelines, commentaries, and articles with less than 20 citations are excluded from any list of classic papers. Many methodological papers become a standard reference that one cites to make clear the kind of work and methodology. Articles that present tools for outcome evaluation or provide classification systems usually result in the most overall citations because these are commonly used in the methodologies of other research studies [37]. Publishing in the English language, and in high impact factor journals are important factors to be considered for a classic paper.

Currently, citation analysis, although biased and idiosyncratic is the best method we have to assess the degree of peer analysis, readership, recognition, importance and impact of the paper, the authors and the publishing journal $[13,17,31$, $33-35,38,39]$. Formulating a method to allow the use of citation analysis to measure scientific quality and to be counted without biases would be ideal.

\section{References}

1. Lu Y, Li S, Wang M (2016) A classification and grading system for Barton fractures. Int Orthop 40(8):1725-1734

2. Fucs PMMB, Scarlat MM (2017) Pediatric Orthopaedics - from Kirschner wires to titanium. Int Orthop 41(12):2429-2431

3. Hernigou P (2017) History of clubfoot treatment; part III (twentieth century): back to the future. Int Orthop 41(11):2407-2414
4. Scarlat MM, Pećina M, Quaile A (2018) High-volume surgeons and high-volume journals in a multivariate orthopedic environment. Int Orthop 42(9):2011-2014

5. Matsumoto T, Nakano N, Lawrence JE, Khanduja V (2019) Current concepts and future perspectives in computer-assisted navigated total knee replacement. Int Orthop 43(6):1337-1343

6. Massari L, Benazzo F, Falez F, Perugia D, Pietrogrande L, Setti S, Osti R, Vaienti E, Ruosi C, Cadossi R (2019) Biophysical stimulation of bone and cartilage: state of the art and future perspectives. Int Orthop 43(3):539-551

7. Scarlat MM (2018) Quality of publications in "international Orthopaedics" and projects for the near future. Int Orthop 42(12): 2735-2736

8. Mavrogenis AF, Quaile A, Scarlat MM (2016) Attractive papers and accurate English. Int Orthop 40(4):649-651

9. Waddell JP, Pečina M, Scarlat MM (2017) Imperfection leads to progress. Int Orthop 41(4):669-670

10. Scarlat MM, Hinsenkamp M, Quaile A, Pecina M (2016) International Orthopaedics is $4 \mathrm{O}$ years old! Int Orthop 40(8): 1563-1569

11. Scarlat MM, Pećina M (2018) Six thousand papers already: "the outcome of a matter is better than its beginning...". Int Orthop 42(5):979-981

12. Quaile A, Scarlat MM, Mavrogenis AF, Mauffrey C (2019) International Orthopaedics - instructions for authors, English expression, style and rules. Int Orthop 43(11):2425-2427

13. Mavrogenis AF, Megaloikonomos PD, Panagopoulos GN, Mauffrey C, Quaile A, Scarlat MM (2017) Best one hundred papers of international Orthopaedics: a bibliometric analysis. Int Orthop 41(4):689-697

14. Sun J, Guo Y, Scarlat MM, Lv G, Yang XG, Hu YC (2018) Bibliometric study of the orthopaedic publications from China. Int Orthop 42(3):461-468

15. Canale ST (2010) In the top 100 classic articles, where's mine? AAOS 20 may 2010; p. 1-1

16. Banaszkiewicz PA, Kader DF (2014) Classic papers in Orthopaedics. Springer-Verlag London

17. Kelly JC, Glynn RW, O'Briain DE, Felle P, McCabe JP (2010) The 100 classic papers of orthopaedic surgery: a bibliometric analysis. J Bone Joint Surg Br 92(10):1338-1343

18. Lowry OH, Rosebrough NJ, Farr AL, Randall RJ (1951) J Biol Chem 193:265-275

19. Campbell FM (1990) National bias: a comparison of citation practices by health professionals. Bull Med Libr Assoc 78:376-382

20. Brooker AF, Bowerman JW, Robinson RA, Riley LH Jr (1973) Ectopic ossification following total hip replacement: incidence and a method of classification. J Bone Joint Surg Am 55-A:16291632

21. Enneking WF, Dunham W, Gebhardt MC, Malawar M, Pritchard DJ (1993) A system for the functional evaluation of reconstructive procedures after surgical treatment of tumors of the musculoskeletal system. Clin Orthop Relat Res 286:241-246

22. Enneking WF, Spanier SS, Goodman MA (1980) A system for the surgical staging of musculoskeletal sarcoma. Clin Orthop Relat Res 153:106-120

23. Garfield E (1955) "Citation indexes for science...". Science. American Association for the Advancement of Science. 122 (3159): 108-111. Bibcode:1955Sci...122..108G. https://doi.org/ 10.1126/science.122.3159.108. PMID 14385826. S2CID 5902162

24. Mavrogenis AF, Panagopoulos GN, Megaloikonomos PD, Panagopoulos VN, Mauffrey C, Quaile A, Scarlat MM (2018) Scientific misconduct (fraud) in medical writing. Orthopedics 41(2):e176-e183

25. Zazgyva A, Kon E, Mauffrey C, Mavrogenis AF, Scarlat MM (2017) Reviews, reviewers and reviewing. Int Orthop 41(1):1-2 
26. Van Noorden R, Maher B, Nuzzo R (2014) The top 100 papers. Nature explores the most-cited research of all time. 29 October 2014. Available at: https://www.nature.com/news/the-top-100papers-1.16224

27. Scarlat MM, Mavrogenis AF, Pećina M, Niculescu M (2015) Impact and alternative metrics for medical publishing: our experience with international Orthopaedics. Int Orthop 39(8):1459-1464

28. Mavrogenis AF, Quaile A, Pećina M, Scarlat MM (2018) Citations, non-citations and visibility of international Orthopaedics in 2017. Int Orthop 42(11):2499-2505

29. Lefaivre KA, Shadgan B, O'Brien PJ (2010) 100 most cited articles in orthopaedic surgery. Clin Orthop Relat Res 469(5):1487-1497

30. Kuhn TS (1962) Historical structure of Scientifi c discovery to the historian discovery is seldom a unit event attributable to some particular man, time, and place. Science 136(3518):760-764

31. Garfield E (1987) 100 citation classics from the journal of the American Medical Association. JAMA Am Med Assoc 257(1): 52-59

32. Picknett T, Davis K (1999) The 100 most-cited articles from JMB. J Mol Biol 293:171-176

33. Baltussen A, Kindler CH (2004) Citation classics in critical care medicine. Intensive Care Med 30(5):902-910
34. Hennessey K, Afshar K, Macneily AE (2009) The top 100 cited articles in urology. Can Urol Assoc J 3(4):293-302

35. Mavrogenis AF, Megaloikonomos PD, Mauffrey C, Scarlat MM, Simon P, Hasegawa K, Fokter SK, Kehr P (2018) The best cited articles of the European journal of Orthopaedic surgery and traumatology (EJOST): a bibliometric analysis. Eur J Orthop Surg Traumatol 28(4):533-544

36. Namdari S, Baldwin K, Kovatch K, Huffman GR, Glaser D (2012) Fifty most cited articles in orthopedic shoulder surgery. J Shoulder Elb Surg 21(12):1796-1802

37. Gheiti AJC, Downey RE, Byrne DP, Molony DC, Mulhall KJ (2012) The 25 most cited articles in arthroscopic orthopaedic surgery. Arthroscopy 28(4):548-564

38. Seglen PO (1997) Citations and journal impact factors: questionable indicators of research quality. Allergy 52:1050-1056

39. Smith R (2008) Beware the tyranny of impact factors. J Bone Joint Surg (Br) 90-B:125-126

Publisher's note Springer Nature remains neutral with regard to jurisdictional claims in published maps and institutional affiliations. 